Chapman University

Chapman University Digital Commons

ESI Working Papers

Economic Science Institute

3-20-2017

\title{
Deception and Reception: The Behavior of Information Providers and Users
}

Roman M. Sheremeta

Chapman University

Timothy W. Shields

Chapman University, shields@chapman.edu

Follow this and additional works at: https://digitalcommons.chapman.edu/esi_working_papers

Part of the Econometrics Commons, Economic Theory Commons, and the Other Economics Commons

\section{Recommended Citation}

Sheremeta, R. M., \& Shields, T. W. (2017). Deception and reception: The behavior of information providers and users. ESI Working Papers 17-04. Retrieved from http://digitalcommons.chapman.edu/esi_working_papers/214/

This Article is brought to you for free and open access by the Economic Science Institute at Chapman University Digital Commons. It has been accepted for inclusion in ESI Working Papers by an authorized administrator of Chapman University Digital Commons. For more information, please contactlaughtin@chapman.edu. 


\title{
Deception and Reception: The Behavior of Information Providers and
} Users

\author{
Comments \\ Working Paper 17-04
}

This working paper was later published as:

Sheremeta, R., \& Shields, T. (2017). Deception and reception: The behavior of information providers and users. Journal of Economic Behavior and Organization, 137, 445-456. doi: 10.1016/j.jebo.2017.03.019 


\title{
Deception and Reception: The Behavior of Information Providers and Users
}

\author{
Roman M. Sheremeta ${ }^{a, b}$ \\ Timothy W. Shields b,c,* \\ ${ }^{a}$ Weatherhead School of Management, Case Western Reserve University, \\ 11119 Bellflower Road, Cleveland, OH 44106 \\ ${ }^{\mathrm{b}}$ Economic Science Institute, Chapman University \\ One University Drive, Orange, CA 92866, USA \\ ${ }^{c}$ Argyros School of Business and Economics, Chapman University, \\ One University Drive, Orange, CA 92866
}

\section{March 2017}

\begin{abstract}
We investigate the behavior of information providers (underwriters) and users (investors) in a controlled laboratory experiment where underwriters have incentives to deceive and investors have incentives to avoid deception. Participants play simultaneously as underwriters and investors in one-shot information transmission games. The results of our experiment show a significant proportion of both deceptive and non-deceptive underwriters. Despite the presence of deceptive underwriters, investors are receptive to underwriters' reports, gleaning information content, albeit overly optimistic. Within our sample, deception by underwriters and reception by investors are the most profitable strategies. Moreover, participants who send deceptive reports to investors, but at the same time are receptive to reports of underwriters, earn the highest payoffs. These results call into question the characterization of duped investors being irrational.
\end{abstract}

Keywords: experiment, strategic communication, risk, deception, investment advice

* Corresponding author: shields@ chapman.edu

We thank the associate editor and three anonymous reviewers for their valuable comments and suggestions. We thank Sukari Farrington, Ola Kvaloy, Marietta Peytcheva, Glenn Pfeiffer, Eric Schniter, Jack Stecher, Nat Wilcox, and seminar participants at Chapman University, the 2013 American Accounting Association Annual Meeting, and the 2016 Experimental Finance North American Meeting for their comments. We also thank the Economic Science Institute at Chapman University for generous financial support. 


\section{Introduction}

Placing trust in experts who have superior and private information is nearly unavoidable. Automotive mechanics advise repairs, attorneys advise whether to pursue legal action, doctors recommend medical procedures, and economists weigh-in on proposed financial reforms. These experts' private information is not necessarily contractible or verifiable. Additionally, they have incentives to act deceptively by charging for superfluous repairs (Olivarez-Giles, 2010; Grover et al., 2013), billing plaintiffs for lawsuits which have little probability of legal remedy, performing unnecessary medical procedures (Johnson \& Rehavi, 2016), or enacting policies that benefit their employers (Carrick-Hagenbarth \& Epstein, 2012).

Conflicts of interest exist in the financial sector where analysts have incentives to earn trading commissions, accountants have incentives to bill for allowable non-audit services, and underwriters have incentives to raise desired capital during public offerings. For example, media reports of the 2012 initial public offering of Facebook suggested that investors were led astray by underwriters who set the share price too high given the underwriters' private unfavorable information (which was purportedly disclosed to some institutional investors). The case is not uncommon in that other research has documented that investors are misled when there are conflicts of interest. Michaely and Womack (1999) attributed the documented bias to conflicts of interest between the analysts and investors, citing both brokerage commissions and the investment banking business as possible sources. Other research also suggests the bias in analysts' reporting is related to conflicts of interests (Cowen et al., 2006; Bradshaw et al., 2013). Malmendier and Shanthikumar (2007) and De Franco and Lu (2007) found evidence of differences in the reaction of investors, suggesting that some investors were misled by deceptive recommendations despite disclosure of conflicts of interests. 
The observed behaviors, deception and reception, are inescapably intertwined. Deception is not possible without a dupable listener, as the very act of deceiving dictates that another was misled. But at the same time, reception is not warranted if deception is certain. If there is no information content in the provider's message, there is no need to listen.

This apparent paradox, simultaneous deceptive and receptive behavior, is the motivation for this research. Using the typology of underwriting, where an underwriter is informed and an investor is information seeking, we investigate if the aforementioned examples are of duped investors, or simply the negative outcomes of gambles taken by rational investors.

To answer these questions, we design an experiment where participants act simultaneously as an informed underwriter and an information seeking investor in one-shot information transmission games. The underwriter is privately informed of the state of nature. Both the underwriter's and investor's payoffs depend upon the state and the investor's action. The underwriter's payoff is greatest when investment is made regardless whether the state is good or bad. The investor's payoff is greatest when investment is made and the state is good. The inherent conflicts of interest provide economic incentives for the underwriter to deceive the investor, and incentives for the investor to avoid deception.

To distinguish behavior based on gleaned information versus distributional preferences, we conducted two treatments. In the first treatment (labeled REAL), participants' payoffs depend upon their own choices and those of other participants in the same experimental session. In the second treatment (labeled ROBOT), participants' payoffs depend upon their own choices and a 'robot', so that participants' decisions could not affect others' payoffs.

Our findings suggest that only a minority of investors is gullible and optimistic. Because underwriters' deception is not absolute (as some underwriters truthfully reveal information about 
the state of the nature), investing conditional upon gleaning information from underwriters' reports results in greater profits than not investing. Furthermore, participants who invest, despite not truthfully revealing their private information as underwriters, earn the greatest economic profit. Ironically, participants who practice deception and reception both yield larger profit.

Our findings provide new evidence for the existence of moral individuals that reject economic incentives to deceive (Hurkens \& Kartik, 2009; Gneezy et al., 2013). Furthermore, we provide evidence that only a minority of investors is overly optimistic about the proportion of moral individuals in the economy. Our design allows us to distinguish this optimism from biases in value estimation and risk preferences. We provide evidence that behavior that might be characterized as investor's gullibility can be a rational response, earning the investor economic profits. Our research also provides a methodological contribution by introducing a design that can provide insights into the determinants of reported biases related to individual's ability to entertain the psychological perspectives of others.

\section{Methods}

\subsection{Background}

If we assume underwriters (senders) and investors (receivers) have no intrinsic cost of lying, and the preferences of underwriters and investors diverge, the equilibrium theory of Crawford and Sobel (1982) predicts underwriters will not transmit all information, but investors cannot be described as misled, as investors should unravel the underwriters' intensions to misrepresent information. Nonetheless, previous experimental studies show that while underwriters tend to adopt deceptive reporting practices, they transmit more information concerning the true state of nature than predicted (Blume et al., 1998; Forsythe et al., 1999; 
Dickhaut et al., 2003; Cai \& Wang, 2006). Sanchez-Pages and Vorsatz (2007) found evidence that one reason for underwriters' behavior is the existence of moral individuals who reject economic incentives to mislead in favor of telling the truth. Other researchers have suggested that some individuals are simply lying-averse (Gneezy, 2005; Hurkens \& Kartik, 2009), guiltaverse (Charness \& Dufwenberg, 2006), sensitive to financial gains (Gibson et al., 2013; Ismayilov \& Potters, 2013), justifiability (Erat, 2013; Erat \& Gneezy, 2011), or motivated by a combination of factors such as financial gains, justifiability and a personal utility of honesty (Sakamoto et al., 2013). Another common finding from experimental literature is that investors rely more on the underwriters' reports than would be expected based on theoretical predictions (Kawagoe \& Takizawa, 2008; Sanchez-Pages \& Vorsatz, 2009). Deception is successful because investors appear receptive.

In summary, both empirical and experimental evidence suggest that even while underwriters tend to adopt deceptive reporting practices, investors act as if they glean information from the underwriters' reports. Furthermore, prior research suggests that even when users of information are aware of conflicts of interests, they fail to discount reports enough (Dickhaut et al., 2003; Cai \& Wang, 2006; Forsythe et al., 1999; Cain et al., 2005, 2011). Excessive credibility is observed not only in underwriter and investor settings, but also in prisoner's dilemmas (Serra-Garcia et al., 2013), trust games (Charness \& Dufwenberg, 2006) and under repeated play (Blume, 2001).

If participants believe others' behavior is the same as their own, then participants in the role of underwriter who reveals the state of nature truthfully would invest in the role of investor. Similarly, those who deceive in the role of underwriter would not invest. Other research suggests participants suffer from a projection effect, where they project their own conjectured behavior 
onto the behavior of others (Ross et al., 1977; Krueger \& Clement, 1994; Epley et al., 2004; Irlenbusch \& Ter Meer, 2013). However, if participants are aware that some fraction of underwriters reveals private information as in the aforementioned studies, an investment strategy conditional upon underwriters' reports might lead to higher profits. That is, a rational participant, who is deceptive in the role of underwriter, might appear trusting (receptive) in the role of investor. Next, we describe the experimental tasks that allow us to tease apart rational from dupable investors.

\subsection{Participants}

The experiment was conducted at the Economic Science Institute. 112 participants were recruited electronically from a standard pool consisting primarily of undergraduate students and randomly assigned into one of two treatments. The student population was $11.5 \%$ Hispanic, 8.5\% Asian, 2\% Black, 65\% Caucasian, 4\% Multiracial, and 9\% others. The average age of the 59 female, 49 male, and 4 transgender participants was approximately 21 years old $(\mathrm{M}=20.15$, $\mathrm{SD}=3.50)$

\subsection{Information Transmission Game}

The experimental design is based on an information transmission game. The game proceeds as follows. In the first stage, the underwriter receives a private perfect signal about the true state of nature. It is public knowledge that the state of the nature is equally likely to be good $(G)$ or bad $(B)$. In the second stage, the underwriter releases a report $\widehat{G}$ or $\hat{B}$ regarding the state of the nature after receiving her signal. After receiving the report, the investor can invest his cash endowment $\eta$, in which case he receives $\pi_{B}<\eta$ when the true state is bad, and $\pi_{G}>\eta$ when 
the state is good. If the investor decides not to invest he retains his endowment. The underwriter earns compensation $\lambda>0$ if the investor decides to invest and nothing otherwise. After the investor makes his decision, the true state of nature is revealed and both players receive their payoffs based on the state and depending on the investment decision of the investor.

Assuming homogenous and selfish preferences, there is either always, or never, investment depending upon the parameter values. Since it is always in the underwriter's interest to persuade the investor to invest, she has an incentive to deceive the investor by sending report $\widehat{G}$ when the true state of nature is bad. Examining only pure strategies, it is trivial to prove truthful reporting cannot be sustained as an equilibrium. Alternatively, imagine the conditions needed for a mixed reporting strategy: the underwriter must be indifferent to reporting $\hat{G}$ or $\widehat{B}$, which dictates the investor use the same investing strategy for both reports. The equilibrium investment strategy is to always or never invest and the equilibrium reporting strategy is to destroy information content such that the investor is indifferent between reports received (A formal proof is available from the authors upon request). Anticipating deception, a risk-neutral investor ignores the underwriter's report and invests only if $\pi_{G} / 2+\pi_{B} / 2 \geq \eta$.

While similar to some existing studies (Forsythe et al., 1999; Dickhaut et al., 2003; Gneezy, 2005; Hurkens \& Kartik, 2009; Sheremeta \& Shields, 2013) our design differs in several important respects. In our experiment, incentives between the investor and underwriter are sometimes aligned (i.e., each party would prefer investment when the state is good). Participants are always informed of the incentives for all roles. An underwriter who saw an unfavorable state but reports a favorable state is always revealed to the investor ex-post, unlike Gneezy (2005) and Hurkens and Kartik (2009). 


\subsection{Measures of Risk}

To infer whether investors extract information content from underwriters' reports we measured investor's risk preferences. In addition to varying the ex-ante expected payoff of investors across four conditions (Table 1), we also asked participants to make decisions in four gambles that are payoff-equivalent to the information transmission game.

Table 1 shows the four conditions of the information transmission game in the experiment. In all conditions, we set the investor's endowment $\eta=\$ 10$, the bad state-based payoff $\pi_{B}=\$ 0$ and the underwriter's compensation $\lambda=\$ 13$. Holding $\pi_{B}$ and $\eta$ fixed, we manipulate $\pi_{G}$ over four conditions (i.e., $\$ 12, \$ 18, \$ 22, \$ 28$ ) such that $\pi_{G} / 2+\pi_{B} / 2<\eta$ in conditions 1 and 2 and $\pi_{G} / 2+\pi_{B} / 2>\eta$ in conditions 3 and 4 . Thus a risk-neutral investor will invest for conditions 3 and 4 even if he believes the underwriter's report contains no information.

Based on Gneezy (2005), Hurkens and Kartik (2009) and Sheremeta and Shields (2013), we conjecture most participants will use deceptive underwriter strategies. Our values $\pi_{G}$ are constructed such that if a participant conjectures all underwriters use deceptive reporting strategies, that participant might invest in conditions 3 and 4 . But if the participant conjectures a majority, but not all, of the underwriters use deceptive reporting strategies, that participant might invest in conditions 2 through 4 . However, if the participant conjectures only a minority, or none, of the underwriters use deceptive reporting strategies, that participant might invest in all conditions.

We use four gambles to elicit participants' risk preferences. Assuming there is no information content in the underwriter's report (i.e. the probability of the state is good is 0.5 ), the gambles are probabilistically equivalent to the four conditions of the information transmission 
game reported in Table 1. In each gamble, participants are asked to state whether they prefer a safe option (equivalent to $\eta$ ) with probability one, or a risky option where the probability of the high value (equivalent to $\pi_{G}$ ) and the low value (equivalent to $\pi_{B}$ ) are equal.

\subsection{Controlling for Distributional Preferences}

To further infer whether choices are based upon participants' anticipation of others' choices, versus based upon distributional preferences (i.e., other-regarding behavior) we used two treatments. In the first treatment, which we label the REAL treatment, participants were paired with other participants in the same session. Thus, participants' choices in the REAL treatment affected the payoffs of other participants. In the second treatment, which we label the ROBOT treatment, participants' payoffs depended upon randomly selected historical choices of participants who were in the REAL treatment. Thus, participants' choices in the ROBOT treatment did not affect payoffs of other participants.

\subsection{Benefits of the Design}

To ascertain whether investors glean information content from underwriter reports, we compare investment and gambling behavior, which prior research suggests is linked (Jadlow \& Mowen, 2010). By controlling for risk preferences, we can ascertain whether investors are gleaning information content from underwriters' report. By manipulating the presence of a partner between treatments, we can ascertain if choices are driven by distributional preferences. ${ }^{1}$

\footnotetext{
${ }^{1}$ Comparison across treatments allows us to separate preferences for others' payoffs from subjective beliefs of others' strategies. In the REAL treatment, participants' decisions are effected by their subjective beliefs of others' strategies, as well as their preferences for others' payoffs. By constructing a 'robot' using observed behavior in REAL treatment, where participants came from the same subject pool, subjective beliefs should be constant across treatments.
} 
By simultaneously acting as underwriters and investors, we capture participant's strategy on multiple parameters before giving feedback. As such, we can ascertain whether the elicited investment strategy is consistent with the same participant's underwriting strategy without the complications of controlling for past outcomes, order effects, or learning about others' strategies.

In the one-shot games of Gneezy (2005) and Sheremeta and Shields (2013) it is difficult to assess if the users of information are optimistic of the truthfulness of reports, as the behavior of an overly optimistic investor is identical to an investor who knows the distribution of underwriters' behavior. Our design measures a participant's responses over multiple parameters, to tease out whether investors are optimistic or not, but at the same time does not give feedback between responses. The design allows us to ascertain whether investment is based upon risk preferences or the result of overly optimistic and gullible behavior. ${ }^{2}$

Eliciting participants' strategies in two roles simultaneously is a trade-off between the objectives of negating repeated-game effects versus the possibility that participants may have erroneous impression they are playing against themselves. We tried to minimize the later effects by explicitly telling participants that they would be paired with other participants and that the computer would randomly select the role and the state of nature for payment. The use of the strategy method also may induce qualitative different behavior than the direct response method (Brandts \& Charness, 2011). Although the above are legitimate concerns, we found that participants' behavior in our experiment is comparable to that in Gneezy (2005) and Hurkens and Kartik (2009).

\footnotetext{
${ }^{2}$ Other researchers examining projection-bias (Krueger \& Clement, 1994; Epley et al., 2004), perspective-bias (Davis et al., 1996; Epley \& Gilovich, 2006), and dilution-bias (Tetlock et al., 1996; Nisbett et al., 2003) may consider a similar design. Comparison of treatments where participants act only in one role to treatments where participates act simultaneously in both roles may illuminate the determinants of these biases (Hoffman \& Patton, 2008; Bowlin et al., 2009).
} 


\subsection{Procedures}

Participants interacted with each other anonymously over a local computer network. The experiment was programmed and conducted using z-Tree (Fischbacher, 2007). The computers were placed within individual cubicles in such a way that all participants could only view their own computer screen.

Each session lasted approximately fifty-five minutes and consisted of 20 to 24 participants. At the beginning of each section, an experimenter read the instructions aloud while each participant followed along with their own copy of the instructions. The instructions explained the experimental procedures, payoffs, and information structures used in the experiment (instructions available in the Appendix). While going over the instructions, participants were asked to write down their answers to several quiz questions to ensure that they understand the instructions. Participants' answers remained confidential to other participants. The experimenter reviewed the correct answers with each participant privately. During and after the instructions were read, participants were prompted to ask the experimenter in private any questions regarding the experimental procedures. While in this manuscript we use the terms 'Good', 'Bad', 'Underwriter', 'Investor', etc., we used neutral terms in the experiment to minimize experimenter demands and unintended normative behavior.

In the first part of the experiment, each participant simultaneously played both roles of underwriter and investor in all four conditions (Table 1) by choosing what report to send for each possible private perfect signal and whether to invest for each possible underwriter's report. That is, for both values of the private signal, the underwriter made a binary choice to reveal the signal truthfully or not. For each possible report, the investor made a binary choice whether to invest (labeled 'Go') or not (labeled 'Stay'). Consequently, each participant was randomly and 
anonymously paired with another participant in the REAL treatment, or assigned a past participant's historical choices in the ROBOT treatment. The computer randomly selected the setting, the role for payment and the state of nature, and determined an outcome for each participant. However, the outcome was not presented until the very end of the experiment, after the second part was completed.

In the second part of the experiment, participants were asked to state whether they prefer a safe or risky option in four gambles equivalent to the four conditions in the information transmission game before knowing the outcome from the first part. Participants were not aware of this task until after they made choices in the first part of the experiment. The outcomes of any choices were not given until the final payment stage in order to minimize any wealth or hedging effects. At the end of the experiment, each participant was paid a $\$ 7$ show-up fee, the payoffs from one randomly selected condition in the first part and one randomly selected gamble in the second part of the experiment. On average participants earned $\$ 18$ in addition to the show-up fee.

\section{Results}

We find no significant differences between the sessions of a treatment. Additionally, we find no significant differences between genders. Therefore, we report the combined results. For all hypothesis tests, we use the choices for each participant, yielding 64 independent observations in the REAL treatment and 48 independent observations in the ROBOT treatment. Unless stated otherwise, we use the Wilcoxon matched-pairs signed-rank test. 


\subsection{Decisions in Information Transmission Games}

In the role of underwriter $20.3 \%$ of participants in the REAL treatment and $14.6 \%$ of participants in the ROBOT treatment always reveal their private information regarding the true state. The difference between treatments is not significant (Mann-Whitney, $\mathrm{Z}=0.70, \mathrm{p}=.44$ ). As shown in Figure 1, most participants report $\widehat{G}$ when the state is good, but also report $\widehat{G}$ when the state is bad. The practice of deception is consistent across conditions; we find no significant differences in underwriters' behavior within participants across conditions (Combined: $\mathrm{Z}=0.00$, $\mathrm{p}=1.00 ;$ REAL: $\mathrm{Z}=0.81, \mathrm{p}=.42 ;$ ROBOT: $\mathrm{Z}=0.57, \mathrm{p}=.56)$.

Result 1: There is a significant proportion of both deceptive and non-deceptive underwriters.

In the role of investor, $92.2 \%$ of participants in the REAL treatment and $91.7 \%$ of participants in the ROBOT treatment invest conditional upon a report $\widehat{G}$ in at least one of the four conditions. ${ }^{3}$ The difference between treatments is not significant (Mann-Whitney, $\mathrm{Z}=0.10$, $\mathrm{p}=.92$ ). As shown in Figure 2, a minority of participants also invests when report is $\hat{B}$ in at least one condition. Mann-Whitney test suggests that those participants who never reveal the state is $B$ tend to invest more often when report is $\hat{B}$ than those who reveal the state is $B$ one or more times $(\mathrm{Z}=1.62, \mathrm{p}=.10)$. These participants may not believe a report $\widehat{B}$ will be sent, as $77 \%$ of those who do invest given a report $\widehat{B}$ never reveal the state is $B$ in the role of underwriter. Investment conditioned upon each report is increasing over conditions, from $62.5 \%$ of investors when $\pi_{G}=$ $\$ 12$ (65.6\% in REAL; $58.3 \%$ in ROBOT), to $89.3 \%$ of investors when $\pi_{G}=\$ 28$ (90.6\% in REAL; $87.5 \%$ in ROBOT). The increase from condition 1 to condition 4 is significant

\footnotetext{
${ }^{3}$ There are several potential explanations for why not all participants send a truthful report when the state is good. First, it could be an outcome of a babbling equilibrium. Second, in could be an indication that some participants simply make mistakes.
} 
(Combined: $Z=5.14, p<.01$; REAL: $Z=3.77, \mathrm{p}<.01$; ROBOT: $Z=3.55$, $\mathrm{p}<.01$ ). Since we find no differences between treatments, in the following sections we explore whether this increase is solely due to higher expected return on investment by examining decisions made in gambles.

\subsection{Decisions in Gambles}

In order to ascertain whether participants glean information content from the underwriters' reports or simply invest based on the investment's fundamental risk, we compare decisions made in gambles to the investment choices. If there is no perceived information content in the underwriters' reports, the exercises are identical. The choices are shown in Figure 3. In all conditions the number of participants investing when the report is $\widehat{G}$ exceeds the number of participants choosing the risky over safe gamble.

Comparing investment conditioned on risk choices, $60.1 \%$ of participants invested despite choosing the safe option in the equivalent gamble, in at least one condition $(59.4 \%$ in REAL; 62.5\% in ROBOT). The difference between treatments is not significant (Mann-Whitney, $\mathrm{Z}=0.33, \mathrm{p}=.74)$. Participants' number of risky choices is less than the number of investment choices (Combined: $\mathrm{Z}=7.67, \mathrm{p}<.01$; REAL: $\mathrm{Z}=5.95$, $\mathrm{p}<.01$; ROBOT: $\mathrm{Z}=4.85$, $\mathrm{p}<.01$ ). This suggests that investors infer information content from underwriters' reports. ${ }^{4}$

Result 2: Investors glean information content from underwriters' reports.

\footnotetext{
${ }^{4}$ Given Bohnet and Zeckhauser (2004) find that individuals state minimum acceptable probabilities of a higher outcome greater when deciding to trust individuals than when taking a risky gamble, we consider this inference conservative.
} 


\subsection{Investors' Optimism}

To provide evidence that perceived information content is optimistic, we examine loglikelihood models of the data, focusing on the investor's choices. This allows us to examine risk preferences in the presence and absence of strategic investment choices, and to capture a measure of perceived information content. As there are no differences in behavior between treatments, we combined treatments for this analysis. ${ }^{5}$

We model investor's utility of payoff as the constant absolute risk aversion (CARA) utility function $U(\pi)=1-e^{-\rho \pi}$, where $\rho$ captures risk preferences and $\pi$ represents the payoff. ${ }^{6}$ The probability that an investor elects the risky option ( 0.5 chance of receiving $\pi_{k}=$ $\{\$ 12, \$ 18, \$ 22, \$ 28\})$ versus the safe option $(\eta=\$ 10)$ is $P_{g}\left(\pi_{k}, \lambda, \rho\right)$, where $\lambda$ is a precision parameter. Following Wilcox (2011), we use a logit-type probability function scaled by the difference between the maximum and the minimum utility value of the specific choice:

$$
P_{g}\left(\pi_{k}, \lambda, \rho\right)=\frac{1}{1+\exp \left[-\frac{\lambda}{U\left(\pi_{k}\right)-U(0)}\left(\frac{1}{2} U\left(\pi_{k}\right)-U(10)\right)\right]}
$$

The log-likelihood of the participants' choice probabilities over the gambles, $X$, is given by:

$$
L L(\lambda, \rho \mid X)=\sum_{i=1}^{112} \ln \prod_{k=1}^{4}\left(x_{k}^{i} P_{g}\left(\pi_{k}, \lambda, \rho\right)+\left(1-x_{k}^{i}\right)\left(1-P_{g}\left(\pi_{k}, \lambda, \rho\right)\right)\right)
$$

where $x_{k}^{i}$ is 1 if participant $i$ chose the risky gamble $k$ over the safe option and 0 otherwise.

Let $z_{k}$ be empirically observed probability that the state is good given the underwriters' report is $G$ for condition $k$. We model investor's subjective probability that the state is good

\footnotetext{
${ }^{5}$ Running the analysis with only observations from the REAL treatment yields similar results. Estimation results are available upon request. Modeling investor utility using other functional forms, such as $\left(\pi^{1-\rho}-1\right) /(1-\rho)$ or $(\pi+0.1)^{1-\rho}-0.1^{1-\rho}$, yields comparable conclusions.

${ }^{6}$ Results are robust to using other utility functions allowing risk aversion. Estimation results are available upon request.
} 
(given that the underwriter's report is $G$ ) as $P_{s}\left(\pi_{k}, \beta\right)=F\left(z_{k} ; \alpha, \beta\right)$, where $F($.$) is the$ cumulative density function of the Beta distribution symmetric about one-half where $\alpha=\beta>0$.

The probability that a player invests given a report $G$ is:

$$
P_{t}\left(\pi_{k}, \lambda, \rho\right)=\frac{1}{1+\exp \left[-\frac{\lambda}{U\left(\pi_{k}\right)-U(0)}\left(P_{s}\left(\pi_{k}, \beta\right) U\left(\pi_{k}\right)-U(10)\right)\right]}
$$

The log-likelihood of the participants' choice probabilities over the gambles, $X$, and choice probabilities over investment choices, $Y$, is given by:

$$
\begin{gathered}
L L(\lambda, \rho, \beta \mid X, Y)=\sum_{i=1}^{112} \ln \left[\prod_{k=1}^{4}\left(x_{k}^{i} P_{g}\left(\pi_{k}, \lambda, \rho\right)+\left(1-x_{k}^{i}\right)\left(1-P_{g}\left(\pi_{k}, \lambda, \rho\right)\right)\right) \times\right. \\
\left.\prod_{k=1}^{4}\left(y_{k}^{i} P_{t}\left(\pi_{k}, \lambda, \rho, \beta\right)+\left(1-y_{k}^{i}\right)\left(1-P_{t}\left(\pi_{k}, \lambda, \rho, \beta\right)\right)\right)\right]
\end{gathered}
$$

where $y_{k}^{i}$ is 1 if participant $i$ choose to invest in condition $k$ and 0 otherwise.

The estimation results of log-likelihood functions (2) and (4) shown in Table 2 support the intuition of the prior section: investment choices are the result of subjective beliefs of others' reporting strategies and not only of task specific risk preferences. The measure for risk preferences $\rho$ is similar when examining only risk choices or all choices. Moreover, the values of $\rho$ given by the two models are not significantly different from each other. Therefore, we argue that the average decision to invest cannot be only due to risk preferences (i.e., gambling), as risk preferences are stable over both models. Rather participants appear to have optimistic beliefs of underwriters' honesty, inferring excessive information content from underwriters' reports.

To illustrate the degree of optimism, we plot the subjective probability function $P_{S}(\pi, \beta)$ at different values of $\beta$ in Figure 4 . When $\beta \rightarrow 0$ the probability function collapses to 0.5 : the prior probability that the state is good and the report has no information content. When, $\beta=1$ the probability function reflects investors having perfect beliefs of underwriters' reporting strategies; they foresee what proportion of other participants honestly reveal the state. When $\beta \rightarrow$ 
$\infty$ the probability function is either one or zero. Given that the observed probability in our experiment, $z_{k}$, is always greater than 0.5 (Table 3 ), a $\beta$ value less than one can be interpreted as pessimism and a value greater than one as optimism. The fitted value is 1.789 , indicating that investors have optimistic beliefs; the subjective beliefs on average are 8 percent higher than observed behavior. The fit of the model given by equation (4) using perfect beliefs (i.e, $\beta=1$ ) yields a log-likelihood fit significantly worse than the fit allowing subjective beliefs to be pessimistic $\left(\mathrm{X}^{2}(1)=6.49, \mathrm{p}=.01\right)$.

Participants tend to invest even in the low expected value conditions. For example, the majority invest in condition $1(62.5 \%$ conditional upon report $\hat{G})$ but the majority of underwriters' do not reveal the unfavorable state in condition $1(28.6 \%)$. Combined with the estimation results of the log-likelihood model, we find investors, on a whole, are optimistic.

Result 3: Investors are overly optimistic of underwriters' truthful reporting.

\subsection{Joint Behavior}

One advantage of our design is that all participants make their decisions both as underwriters and as investors. In Figure 5 participants are classified as 'non-deceptive' if in the role of underwriter they report $\hat{G}$ if the state is good in at least three of four conditions and reported $\hat{B}$ when the state is bad in at least three of four conditions. Otherwise the classification is 'deceptive'. Correspondingly, participants are classified as 'receptive' if in the role of investor they invest conditional on a report $\hat{G}$ in at least three of four conditions and do not invest conditional on a report $\widehat{B}$ in at least three of four conditions, else the classification is "nonreceptive'. 
Akin to Irlenbusch and Ter Meer (2013) we find behavior is consistent with theories of projection bias. The number of conditions where a participant reveals the state is $B$ is positively correlated with the number of investments conditional on the report $\widehat{G}$ (Spearman $\rho=0.2453, \mathrm{p}<$ .01). A Mann-Whitney test shows that the participants classified as 'non-deceptive' invest significantly more often $(M=3.74, M d n=4, N=27)$ than those classified as 'deceptive' $(M=2.91$, $\mathrm{Mdn}=3, \mathrm{~N}=85), \mathrm{Z}=2.86, \mathrm{p}<.01$. Nonetheless, we find a large proportion of participants are classified as deceptive yet receptive of others' reports. That is, the participant's choice as an investor is not the best response to his or her own behavior as an underwriter (those participants classified in the upper left and lower right quadrants of Figure 5). This observation is confirmed by statistical analysis where the null hypothesis that behavior is consistent over roles is rejected $(\mathrm{Z}=4.93, \mathrm{p}<.01)$

Result 4: Participants' investment strategy is not always a best response to their own reporting strategy.

\subsection{Comparison of Payoffs}

As previously discussed, prior research shows that participants reveal more information concerning the true state of nature than predicted. Assume that participants are aware of this fact. There is some fraction, $\alpha$, of underwriters who are 'non-deceptive', i.e., they reveal a bad state despite economic incentives not to. The remainder, $1-\alpha$, is 'deceptive' and always report that the state is good. First we conjecture this to be the reporting strategy. If $\alpha>0$, then it turns out that this reporting strategy weakly dominates randomizing between reports and as such the conjecture

is confirmed. As a consequence, there is some information content in both reports $\widehat{G}$ and $\hat{B}$. When the report is $\widehat{G}$ the expected utility for a risk-neutral rational investor from investing is 
$\operatorname{Pr}(G \mid \widehat{G}) \pi_{G}+\operatorname{Pr}(B \mid \widehat{G}) \pi_{B}$. Given $\pi_{B}=0$ and the states are equally likely, the expected utility reduces to $\frac{1}{2-\alpha} \pi_{G}$. The expected utility of not investing is always $\$ 10$. The only way an underwriter would report $\hat{B}$ is if he/she was non-deceptive and the state was actually $B$. As such a report $\hat{B}$ is reliable, and there should be no investment. ${ }^{7}$

If investors believe there are enough participants who are non-deceptive (i.e., $\alpha$ is high enough), then investment increases investors' expected utility. For example, when $\alpha$ is $1 / 5$ and $\pi_{G}$ is $\$ 18$, the expected utility to a risk neutral agent from investing is equal to that of not investing. In our experiment $17.6 \%$ of participants always revealed the state. For this parameter value $\left(\pi_{G}\right.$ is $\left.\$ 18\right)$, it is the best response for a risk neutral deceptive participant not to use an investment strategy that is a best respond to his/her own reporting strategy.

Using the classification in the prior section, we find $19.6 \%$ of participants are nondeceptive and receptive, $33.0 \%$ are deceptive yet receptive, and $42.9 \%$ are deceptive and nonreceptive (see Figure 5). The remaining $4.45 \%$ of participants are non-deceptive yet nonreceptive.

How did these types perform economically in our experiment? We compute expected payoff assuming risk neutrality, which appears reasonable given the risk parameter $(\rho)$ estimates

\footnotetext{
${ }^{7}$ A framework of hierarchical thinking is also consistent with the observed behavior, albeit this requires more assumptions. Assume participants' strategies are best responses to beliefs of others' strategies, but in contrast to standard equilibrium predictions, those beliefs can be erroneous, and thus, off-equilibrium. Define a base-line strategy that is used by a type- 0 participant. Further, assume the participant is non-strategic in a profit maximizing sense, albeit not necessarily naïve or unsophisticated. If the participant is an underwriter, the strategy is to always report the state honestly. Define this reporting strategy as R0. At the same time, the investor's strategy is to invest when the underwriter's report is $\widehat{G}$, but to not invest when the underwriter's report is $\hat{B}$. Define this investing strategy as I0. Participants using strategies that constitute best responses to R0 and IO are denoted as type-1. If investors use an I0 strategy, then all reports should be $\hat{G}$. Define this strategy as R1. If underwriters use R0, then the best response for investors is to invest when the underwriter's report is $\hat{G}$ but not when the underwriter's report is $\hat{B}$. Define this strategy as I1. Participants using strategies that constitute best responses to R1 and I1 are denoted as type-2. If underwriters use R1, then the best response is not to glean any information from the underwriter's report. Define this strategy as I2. If investors use I1, then all reports should be $\hat{G}$. All subsequent iterations yield strategies of no investment.
} 
from the log-likelihood models. The calculation of the expected payoff of an underwriter uses the participant's reporting strategy and all other participants' investing strategies. Similarly, the calculation of the expected payoff of an investor uses the participant's investing strategy and all other participants' reporting strategies. A Mann-Whitney test verifies that the expected payoff of deceptive underwriters who always report $\widehat{G}$, summed over all conditions $(\mathrm{M}=20.82, \mathrm{~N}=57)$, is significantly higher than the payoff of other underwriters $(\mathrm{M}=17.33, \mathrm{~N}=55), \mathrm{Z}=5.69, \mathrm{p}<.01$.

The payoff of receptive investors who invest conditional on report $\widehat{G}$ a majority of the time, summed over all conditions $(M=43.99, N=59)$, is significantly greater than the payoff of other investors $(\mathrm{M}=41.57, \mathrm{~N}=53), \mathrm{Z}=4.99, \mathrm{p}<.01$. This result is also robust when excluding those investors who invest condition on report $\widehat{B} ; \mathrm{Z}=3.18, \mathrm{p}<.01$. As a consequence, deceptive and receptive strategies yield the highest economic return. The return is even greater for the subset of participants who display some level of skepticism and invest only in conditions 2-4 (Mdn=45.66, $\mathrm{N}=16$ ) than those who invest in all conditions ( $\mathrm{Mdn}=43.36, \mathrm{~N}=43), \mathrm{Z}=6.18, \mathrm{p}<.01$.

Result 5: Deceptive underwrites and receptive investors earn the highest payoffs.

\section{Discussion and Conclusion}

We investigate the behavior of underwriters and investors in a controlled laboratory experiment where underwriters have incentives to deceive and investors have incentives to avoid deception. The results of our experiment show a significant proportion of both deceptive and non-deceptive underwriters. Those underwriters who are deceptive earn higher profits than nondeceptive underwriters. Despite the presence of deceptive underwriters, investors are receptive to underwriters' reports, gleaning information content, albeit investors appear overly optimistic. Those investors who are receptive earn higher profits than non-receptive investors. However, 
akin to an attitude of professional skepticism, investors exhibiting conditional skepticism earn the greatest profits.

The investors who invest in the projects with lower expected returns (i.e., conditions 1 and 2), on average, earn higher payoffs than those who do not. This is despite the fact that economic theory predicts the opposite. Investors who invest in at least three of four conditions clearly earn more than others even though the same participants are not playing a best response to their own behavior. Their behavior is inconsistent with a projection bias. It is as if some participants realize that some fraction of the underwriters is honest, and consequently choose to invest as a best response to such beliefs. In a crude sense, reception pays off, but, ironically so does deception. Comparing behavior between treatments, it appears that investment behavior is not a function of distributional concerns (i.e., other-regarding preferences), but a subjective belief that underwriters are honest 'enough' to warrant investment.

The results have an interesting implication for disclosing conflicts of interests in one-shot events such as underwriting. If disclosure of conflicts of interests is mandated in order to discipline deceptive behavior, the existence of naturally honest underwriters and consequently, naturally receptive investors, impedes the disciplinarian intent of disclosure. If informed investors cannot help but to listen because there are honest underwriters, then the lack of collective skepticism cannot in itself discipline underwriters. 


\section{References}

Blume, A. (2001). Evolution of communication with partial common interest. Games and Economic Behavior, 37(1), 79-120.

Blume, A., DeJong, D.V., Kim, Y.G., and Sprinkle, G.B. (1998). Experimental evidence on the evolution of meaning of messages in sender-receiver games. American Economic Review, 88(5), 1323-1340.

Bohnet, I., and Zeckhauser, R. (2004). Trust, risk and betrayal. Journal of Economic Behavior \& Organization, 55(4), 467-484.

Bowlin, K.O., Hales, J.W., and Kachelmeier, S.J. (2009). Experimental evidence of how prior experience as an auditor influences managers' strategic reporting decisions. Review of Accounting Studies, 14(1), 63-87.

Bradshaw, M., Brown, L., and Huang, K. (2013). Do sell-side analysts exhibit differential target price forecasting ability? Review of Accounting Studies, 18, 930-955.

Brandts, J. and Charness, G. (2011). The strategy versus the direct-response method: A first survey of experimental comparisons. Experimental Economics, 14(3), 375-398.

Cai, H. and Wang, J.T.Y. (2006). Overcommunication in strategic information transmission games. Games and Economic Behavior, 56(1), 7-36.

Cain, D.M., Loewenstein, G., and Moore, D.A. (2005). The dirt on coming clean: Perverse effects of disclosing conflicts of interest. Journal of Legal Studies, 34(1), 1-25.

Cain, D.M., Loewenstein, G., and Moore, D.A. (2011). When sunlight fails to disinfect: Understanding the perverse effects of disclosing conflicts of interest. Journal of Consumer Research, 37(5), 836-857.

Carrick-Hagenbarth, J. and Epstein, G.A. (2012). Dangerous interconnectedness: economists' conflicts of interest, ideology and financial crisis. Cambridge Journal of Economics, 36(1), 43- 63.

Charness, G. and Dufwenberg, M. (2006). Promises and partnership. Econometrica, 74(6), 15791601.

Cowen, A., Groysberg, B., and Healy, P. (2006). Which types of analyst firms are more optimistic? Journal of Accounting and Economics, 41(1-2), 119-146.

Crawford, V. and Sobel, J. (1982). Strategic information transmission. Econometrica, 50(6), 1431-1451.

Davis, M.H., Conklin, L., Smith, A., and Luce, C. (1996). Effect of perspective taking on the cognitive representation of persons: A merging of self and other. Journal of Personality and Social Psychology, 70(4), 713-726.

De Franco, G. and Lu, H. (2007). Wealth transfer effects of analysts' misleading behavior. Journal of Accounting Research, 45(1), 71-110.

Dickhaut, J., Ledyard, M., Mukherji, A., and Sapra, H. (2003). Information management and valuation: an experimental investigation. Games and Economic Behavior, 44, 26-53.

Epley, N. and Gilovich, T. (2006). The anchoring-and-adjustment heuristic: Why the adjustments are insufficient. Psychological Science, 17(4), 311-318.

Epley, N., Keysar, B., Van Boven, L., and Gilovich, T. (2004). Perspective taking as egocentric anchoring and adjustment. Journal of Personality and Social Psychology, 87(3), 327-339.

Erat, S. (2013). Avoiding lying: The case of delegated deception. Journal of Economic Behavior \& Organization, 93, 273-278.

Erat, S. and Gneezy, U. (2011). White lies. Management Science, 58(4), 723-733. 
Fischbacher, U. (2007). z-Tree: Zurich toolbox for ready-made economic experiments. Experimental Economics, 10(2), 171-178.

Forsythe, R., Lundholm, R., and Rietz, T. (1999). Cheap talk, fraud, and adverse selection in financial markets: Some experimental evidence. Review of Financial Studies, 12(3), 481518.

Gibson, R., Tanner, C., \& Wagner, A. F. (2013). Preferences for truthfulness: Heterogeneity among and within individuals. American Economic Review, 103(1), 532-548.

Gneezy, U. (2005). Deception: The role of consequences. American Economic Review, 95(1), 384-394.

Gneezy, U., Rockenbach, B., and Serra-Garcia, M. (2013). Measuring lying aversion. Journal of Economic Behavior \& Organization, 93, 293-300.

Grover, J., Henao, C., and Drechsler, P. (2013). "You were robbed": NBC4 I-team exposes new "tricks and tactics" at Jiffy Lube stores. NBC4 Los Angeles.

Hoffman, V. B. and Patton, J. M. (2008). Accountability, the dilution effect, and conservatism in auditors' fraud judgments. Journal of Accounting Research, 35(2), 227-237.

Hurkens, S. and Kartik, N. (2009). Would I lie to you? On social preferences and lying aversion. Experimental Economics, 12(2), 180-192.

Irlenbusch, B. and Ter Meer, J. (2013). Fooling the nice guys: Explaining receiver credulity in a public good game with lying and punishment. Journal of Economic Behavior \& Organization, 93, 321-327.

Ismayilov, H. and Potters, J. (2013). Disclosing advisor's interests neither hurts nor helps. Journal of Economic Behavior \& Organization, 93, 314-320.

Jadlow, J.W. and Mowen, J.C. (2010). Comparing the traits of stock market investors and gamblers. Journal of Behavioral Finance, 11(2), 67-81.

Johnson, E.M., \& Rehavi, M.M. (2016). Physicians treating physicians: Information and incentives in childbirth. American Economic Journal: Economic Policy, 8(1), 115-141.

Kawagoe, T. and Takizawa, H. (2008). Equilibrium refinement vs. level-k analysis: An experimental study of cheap-talk games with private information. Games and Economic Behavior, 66(1), 238-255.

Krueger, J. and Clement, R.W. (1994). The truly false consensus effect: An ineradicable and egocentric bias in social perception. Journal of Personality and Social Psychology, 67(4), 596-610.

Malmendier, U. and Shanthikumar, D.M. (2007). Are small investors naive about incentives? Journal of Financial Economics, 85(2), 457-489.

Michaely, R. and Womack, K. L. (1999). Conflict of interest and the credibility of underwriter analyst recommendations. Review of Financial Studies, 12(4), 653-686.

Nisbett, R.E., Zukier, H., and Lemley, R.E. (2003). The dilution effect: Nondiagnostic information weakens the implications of diagnostic information. Cognitive Psychology, 13(2), 248-277.

Olivarez-Giles, N. (2010). Owner of 22 Midas auto repair shops settles fraud allegations. Los Angeles Times.

Ross, L., Greene, D., and House, P. (1977). The "false consensus effect": An egocentric bias in social perception and attribution processes. Journal of Experimental Social Psychology, 13(3), 279-301. 
Sakamoto, K., Laine, T., and Farber, I. (2013). Deciding whether to deceive: Determinants of the choice between deceptive and honest communication. Journal of Economic Behavior \& Organization, 93, 392-399.

Sanchez-Pages, S. and Vorsatz, M. (2007). An experimental study of truth-telling in a senderreceiver game. Games and Economic Behavior, 61(1), 86-112.

Sanchez-Pages, S. and Vorsatz, M. (2009). Enjoy the silence: an experiment on truth-telling. Experimental Economics, 12(2), 220-241.

Serra-Garcia, M., van Damme, E., and Potters, J.J. (2013). Lying about what you know or about what you do? Journal of the European Economic Association, 11(5), 1204-1229.

Sheremeta, R.M. and Shields, T. (2013). Do liars believe? Beliefs and other-regarding preferences in sender-receiver games. Journal of Economic Behavior \& Organization, 94, 268-277.

Tetlock, P.E., Lerner, J.S., and Boettger, R. (1996). The dilution effect: Judgmental bias, conversational convention, or a bit of both? European Journal of Social Psychology, 26, 915-934.

Wilcox, N. (2011). 'Stochastically more risk averse:' A contextual theory of stochastic discrete choice under risk. Journal of Econometrics, 162(1), 89-104. 
Figure 1: Choices of Underwriters in Four Conditions by Treatment

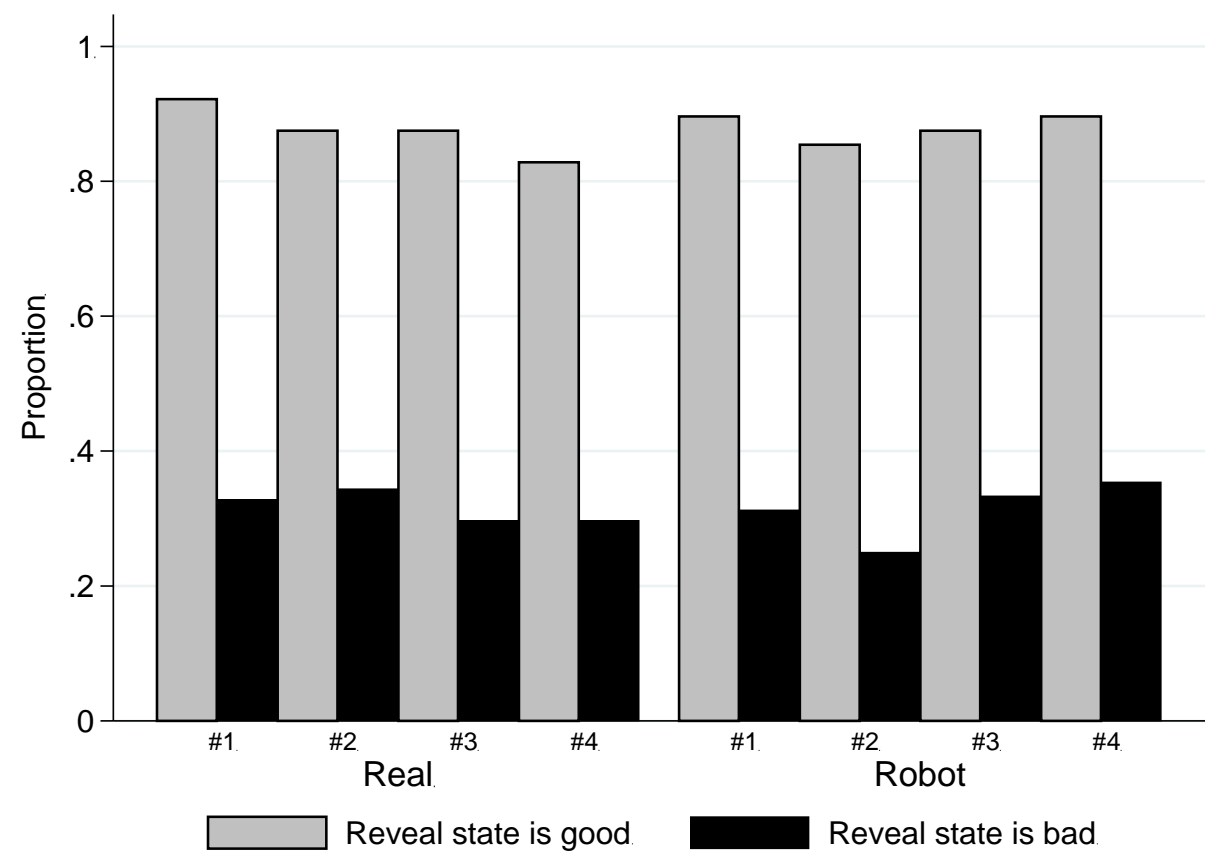

The figure shows the proportion of underwriters who honestly reveal that the state is good, and the proportion who honestly reveal that the state is bad. There are 64 underwriters in the REAL treatment and 48 in the ROBOT treatment. 
Figure 2: Choices of Investors in Four Conditions by Treatment

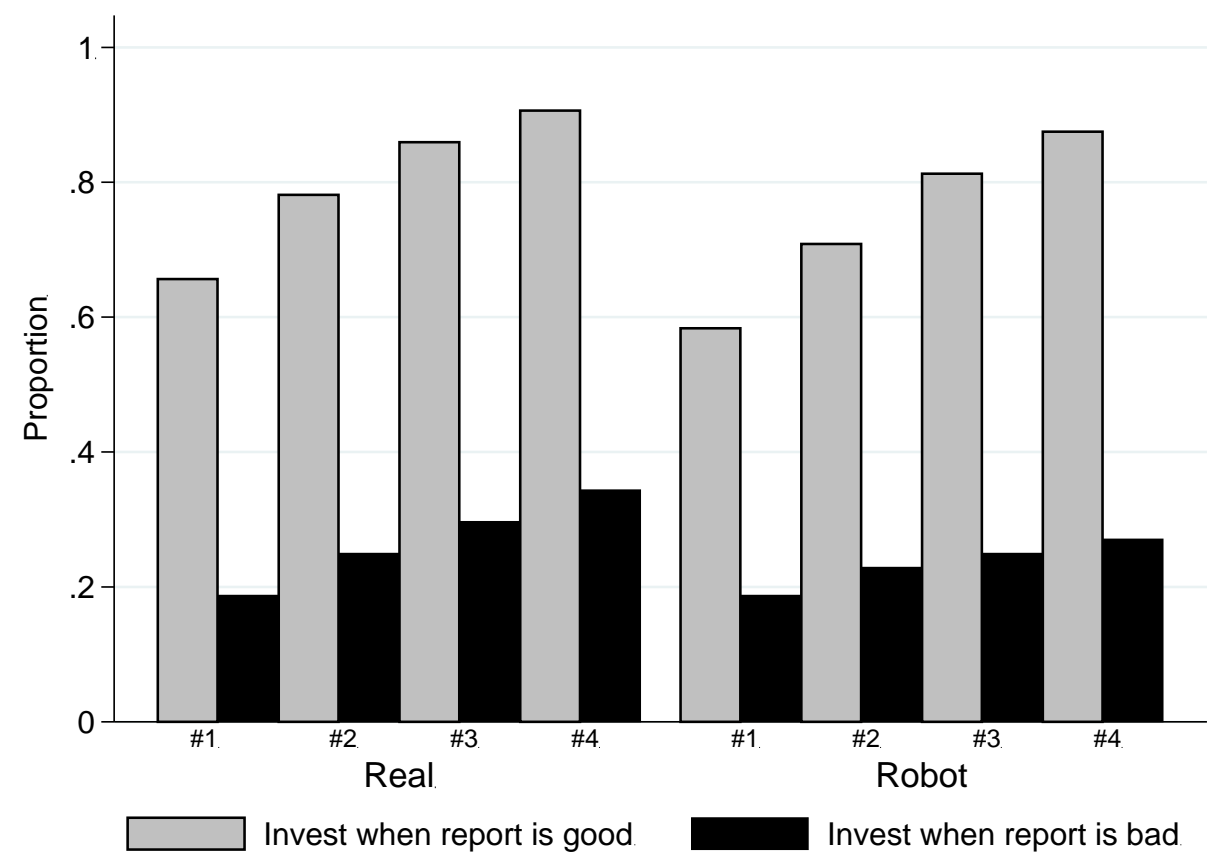

The figure shows the proportion of investors who invest when report is good, and when it is bad. There are 64 investors in the REAL treatment and 48 in the ROBOT treatment. 
Figure 3: Investment and Gambles in Four Conditions by Treatment

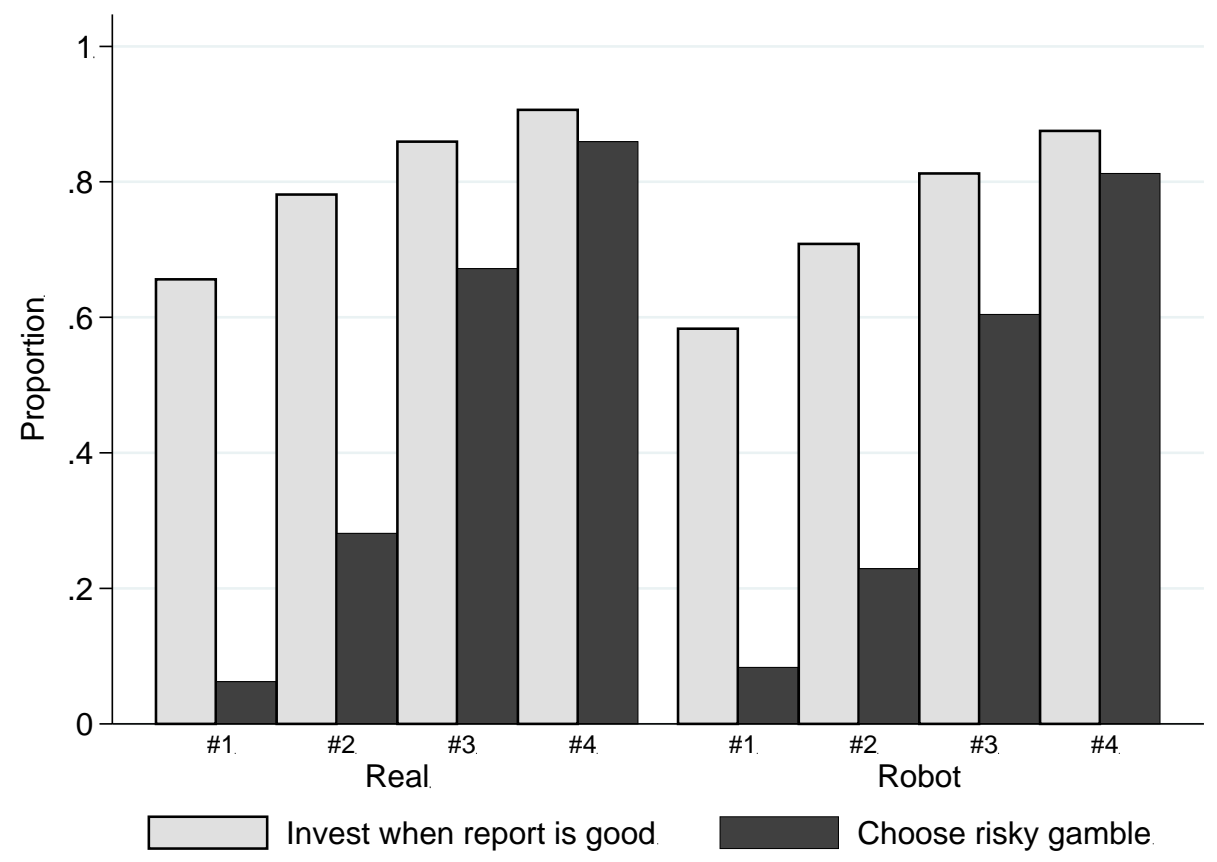

The figure shows the proportion of investors who invest when report is good, and the proportion of investors who choose the corresponding risky gamble. There are 64 investors in the REAL treatment and 48 in the ROBOT treatment. 
Figure 4: Subjective Probability Distribution

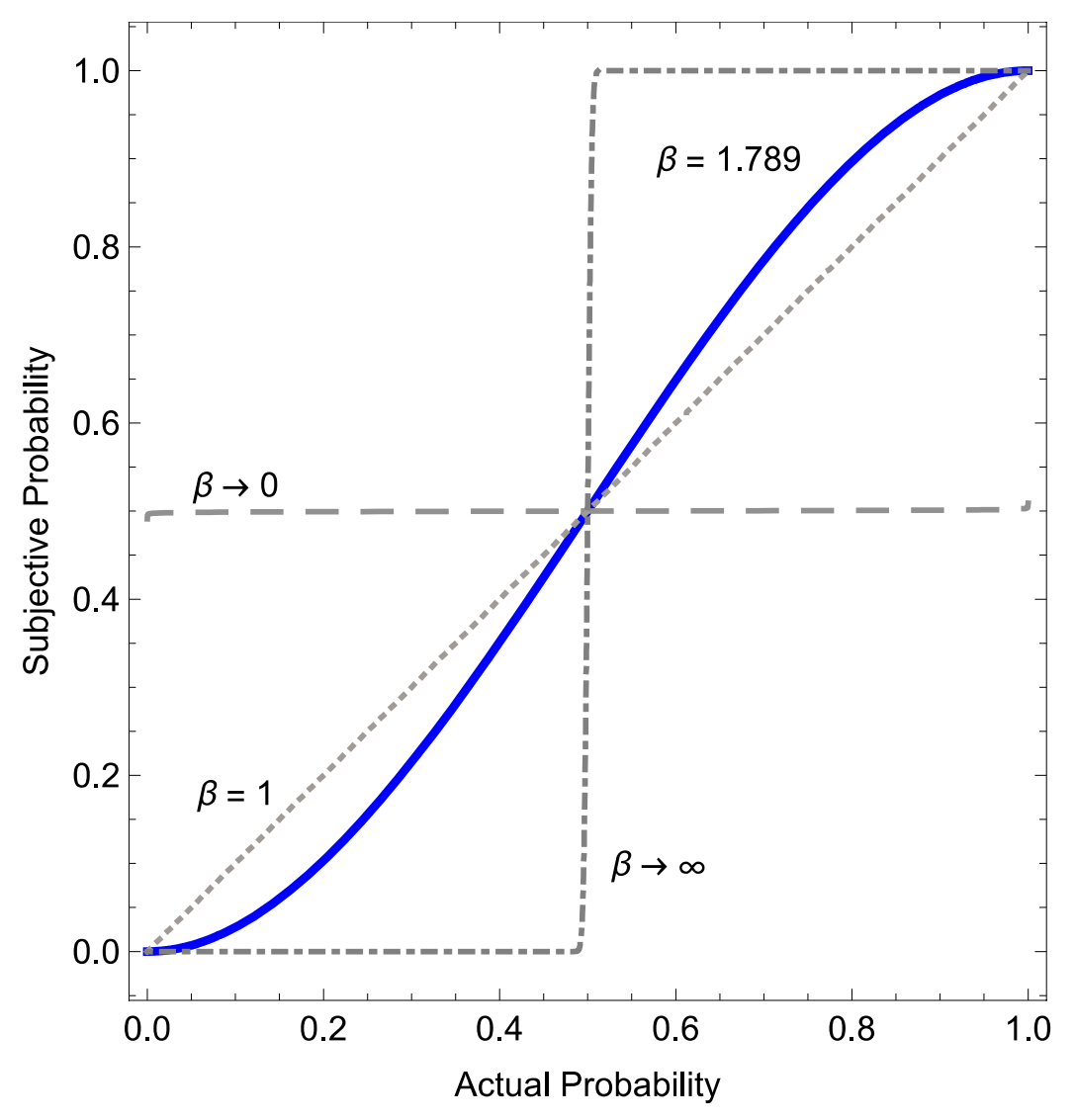

The figure illustrates investors' subjective probabilities in scenarios when investors (1) glean no information content $(\beta \rightarrow 0)$, (2) have perfect beliefs of others' reporting strategies $(\beta=1)$, (3) hold extreme beliefs leading to probability of one or zero $(\beta \rightarrow \infty)$. The fitted value of $\beta$ reflects the optimistic beliefs of underwriters' honesty as derived from maximization of the loglikelihood model. 


\section{Figure 5: Joint Behavior as Underwriter and Investor}

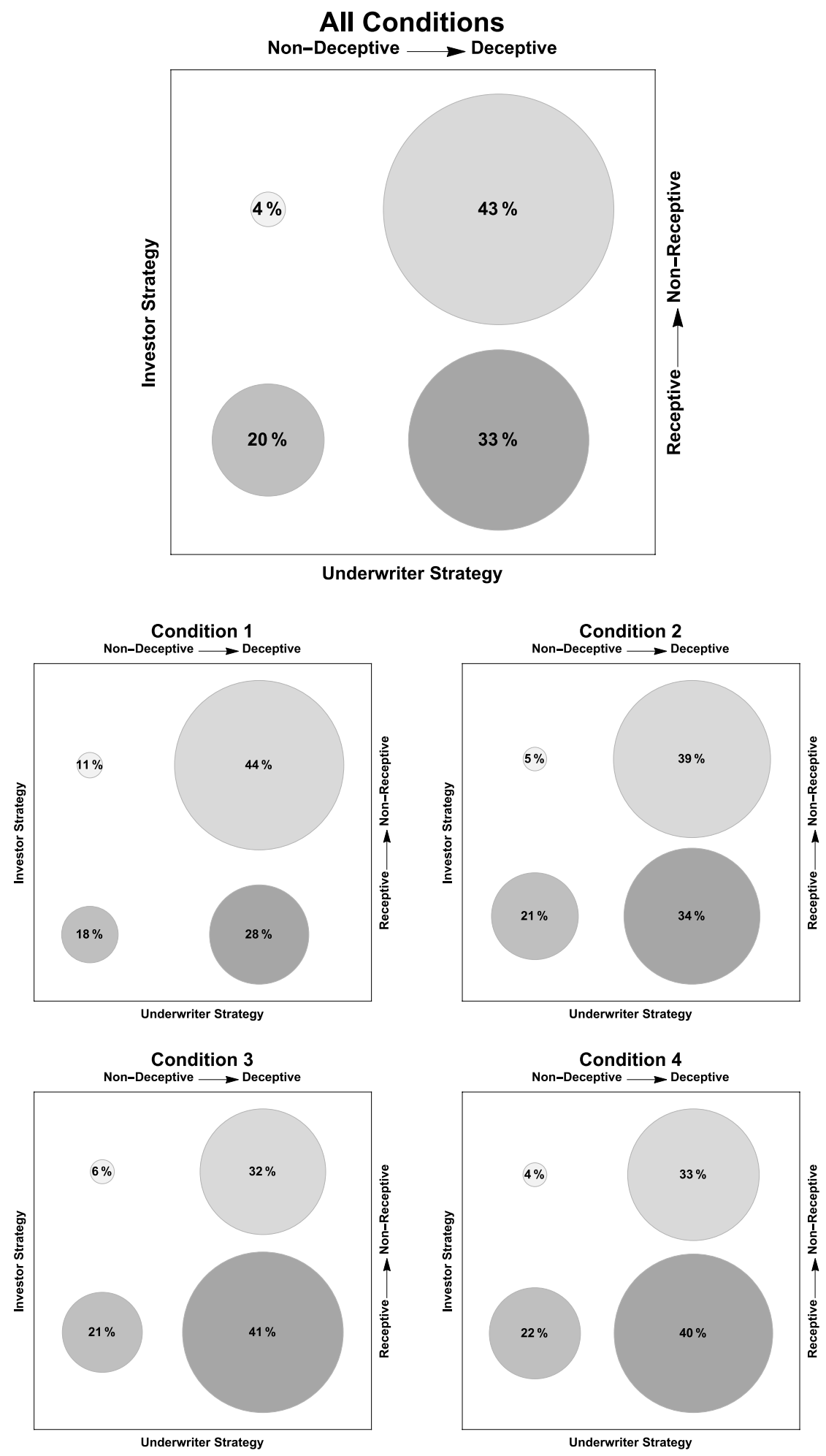

The figures show behavior in both roles, broken out per condition, and averaged over all conditions. 
Table 1: Parameter Values for Conditions

\begin{tabular}{lccc}
\hline \hline & Endowment & \multicolumn{2}{c}{ Investment Payoff } \\
\cline { 3 - 4 } & $\eta$ & $\pi_{B}$ & $\pi_{G}$ \\
\hline Condition 1 & 10 & 0 & 12 \\
Condition 2 & 10 & 0 & 18 \\
Condition 3 & 10 & 0 & 22 \\
Condition 4 & 10 & 0 & 28 \\
\hline Note: All payoffs reported in US\$. In all conditions $p(G)=p(B)=0.5$.
\end{tabular}

Table 2: Maximum Likelihood Model Best Fit Parameters

\begin{tabular}{lcccc}
\hline \hline Log-likelihood & Function Value & $\lambda$ & $\rho$ & $\beta$ \\
\hline$L L(\lambda, \rho \mid X)$ & -220.49 & 9.97 & 0.0003 & \\
& & $(0.11)$ & $(0.0005)$ & \\
$L L(\lambda \rho, \beta \mid X, Y)$ & -464.50 & 5.72 & 0.0002 & 1.789 \\
& & $(0.06)$ & $(0.0005)$ & $(0.045)$ \\
\hline
\end{tabular}

SEM is reported in parenthesis. Simulated SEM were generated by simulating 1,000 sets of investment and/or gamble decisions given by equations (1) and (3) over 4 conditions using the reported fitted parameters. Best fit parameters for 112 iterations were used to report SEM.

Table 3: Subjective and Actual Probability of Good State Given Report $\widehat{G}$

\begin{tabular}{lcccc}
\hline \hline Value of $\pi_{G}$ & 12 & 18 & 22 & 28 \\
\hline Subjective probability $P_{S}\left(\pi_{K}, \beta\right)$ & 0.816 & 0.818 & 0.814 & 0.802 \\
Actual probability $z_{k}$ & 0.739 & 0.740 & 0.736 & 0.727 \\
Optimism $P_{S}\left(\pi_{K}, \beta\right)-z_{k}$ & 0.077 & 0.078 & 0.077 & 0.075 \\
\hline
\end{tabular}

Note: Subjective probability is estimated at fitted parameter values. 


\section{Appendix A (For Online Publication)}

\section{Experimental Instructions: REAL treatment}

This is a computerized experiment in the economics of decision-making. By following the instructions carefully and making good decisions, you may earn an additional amount of money besides the show up bonus of \$7. The currency used in this experiment is the unit lira. Lira will be converted to dollars at the end of the experiment; the conversion rate is on the board. The actual amount of additional money that you may earn will depend on your decisions and the decisions of other participants. Your money will be paid to you in cash after the experiment ends.

There are some rules you must follow: (1) Do not talk to others at any time during the experiment. (2) You will use your computer to select decisions during the experiment. Do not use your mouse or keyboard to play around with the software running on your computer. If you unintentionally or intentionally close the software program running on your computer, you will be asked to leave. If this happens, you will receive only your show up bonus. (3) If you have any questions during the experiment or instructions, please raise your hand. An experimenter will come to your location and answer your questions.

\section{Details of the Experiment Grouping of Participants}

The experiment consists of a single round. Within this round you will be randomly paired with up to eight other participants, but into separate groupings. There are four settings. Within each setting there will be a single Sender and a single Receiver. You will make decisions both as a Sender and Receiver in all settings. These settings are separate, as your decisions in one setting or role will not affect what happens in the other settings.

You will never be told whom you are paired with. You are not allowed to communicate with others during the experiment.

\section{Overview of the Setting}

Each Receiver has one unit of the financial asset. At the end of each round, the computer determines the State of the economy, which in turn dictates the value of each Receiver's asset. The chances of a particular State are:

Chances of States

\begin{tabular}{|l|l|l|}
\hline State & A & B \\
\hline Chance of State & $1 / 2$ & $1 / 2$ \\
\hline
\end{tabular}

The State will be either A or B. There is an equal chance that the computer will select A or B. So, on average the computer will select A 50 percent of the time and B 50 percent of the time.

At the beginning of each round the Sender privately learns the State. No one else learns the State before the end of the round.

After the Sender learns the State, the Sender sends a Report to the Receiver. After the Receiver sees the Sender's Report, the Receiver decides to Go or Stay resulting in the following payoffs.

Payoffs Given State and Receiver's Decisions

\begin{tabular}{|l|l|l|}
\hline State is & A & B \\
\hline \multicolumn{3}{|c|}{ Receiver decides to Go } \\
\hline Receiver & X & 0 \\
\hline Sender & 13 & 13 \\
\hline \multicolumn{3}{|c|}{ Receiver decides to Stay } \\
\hline Receiver & 10 & 10 \\
\hline Sender & 0 & 0 \\
\hline
\end{tabular}

The value of $X$ depends upon the setting. It will either be 12, 18, 22, or 28 .

Notice that only when the State is A are the payoffs higher for all parties when the Receiver decides to Go rather than to Stay. Also, notice that the payoff is higher for the Sender if the Receiver decides to Go rather than to Stay in both States A and B. Last, notice that the payoffs do not depend on the Sender's Report, only on the State and whether the Receiver decides to Go or Stay.

What is the Sender's Report? If the Sender learns the State is A, the Sender can decide to report either A or B. If the Sender learns the State is B, the Sender can decide to Report A or B. 


\section{Questionnaire 1}

Below, please write down your answers to the following questions. If you have a question, please raise your hand and an experimenter will privately answer your question. In a few minutes, an experimenter will review the correct answers.

1) What is the chance the State will be $B$ ? $(0,1 / 2,1)$

2) If the Sender knows the State is B, what can she report? (A, B, A or B)

3) If the Receiver knew the State was A, is his payment higher if he chooses to Go? (Yes, No)

4) If the Receiver knew the State was B, is his payment higher if he chooses to Go? (Yes, No)

5) If the Receiver decides to Go, what will the Sender receive? $(\$ 10, \$ 13)$

\section{Sender's Decision}

We will ask you to make a decision in the role of Sender in four settings. In each setting the payoff to the receiver if he goes in State A is 12,18,22, or 28. Specifically, we will ask you to make a decision about what you would report to the paired Receiver in advance of seeing the State drawn. When the experiment starts you will see the following on your screen:

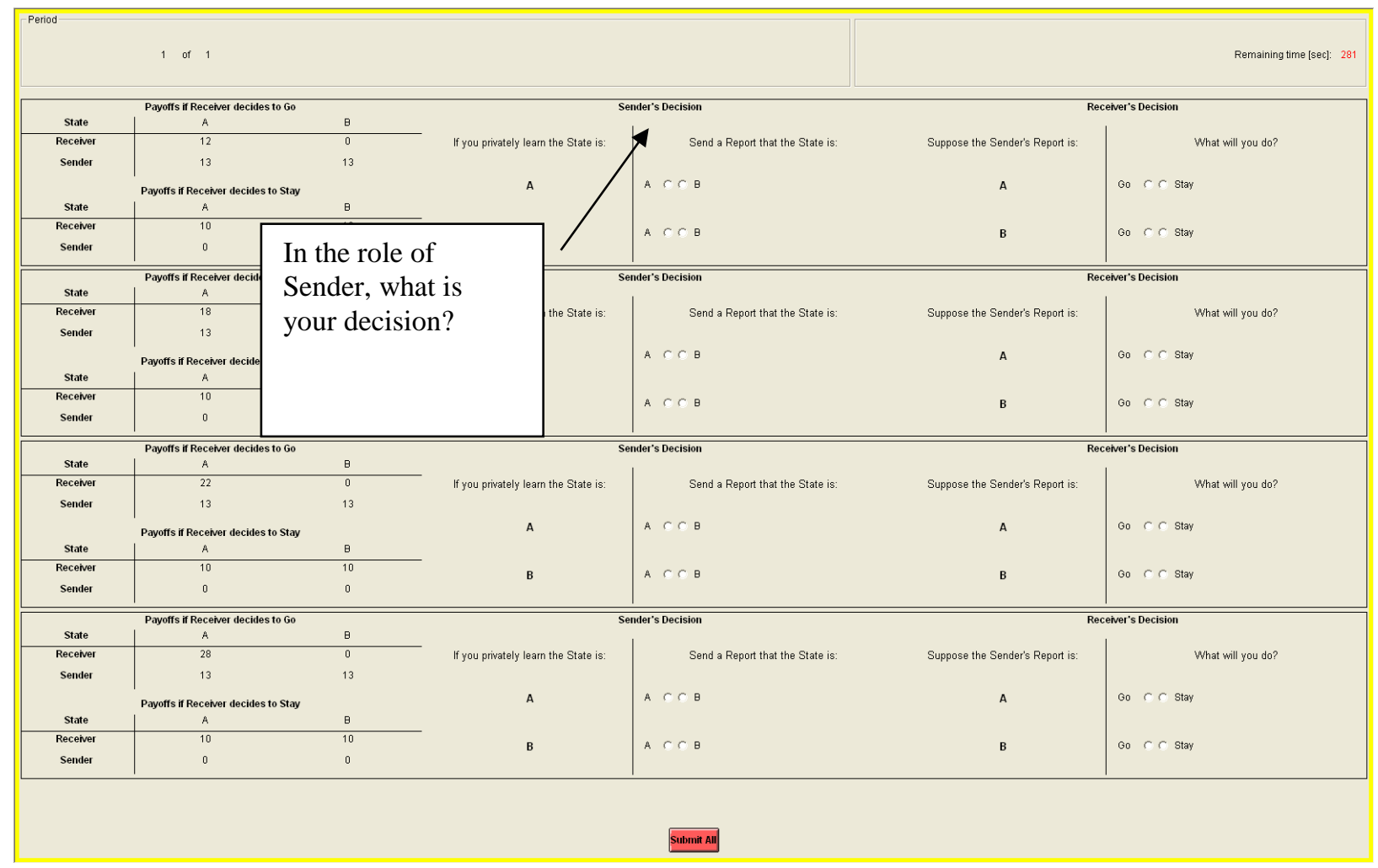

On the left side of the screen you are asked as a Sender to fill in the two entries for each of four settings. If the State were equal to A, would you report A or B, and if the State were equal to B, would you report A or B? Specifically, for each possible State, you need to tell the computer what Report you will send.

We want you, as the Sender, to say in advance what you would do in both of the scenarios. The computer implements the decisions you make once the State is drawn. Your decision will not affect which State is drawn. Your decision in the role of Sender will not affect the outcome of the settings in which you are a Receiver. Your decision will note effect the other settings.

\section{Receiver's Decision}

We will ask you to make a decision in the role of Receiver in four settings. In each setting the payoff to the receiver in State A is 12, 18, 22, or 28 if he goes. Specifically, we will ask you to make a decision about what you 
would do for each possible Report the paired Sender might send before you see the Report. When the experiment starts you will see the following on your screen:

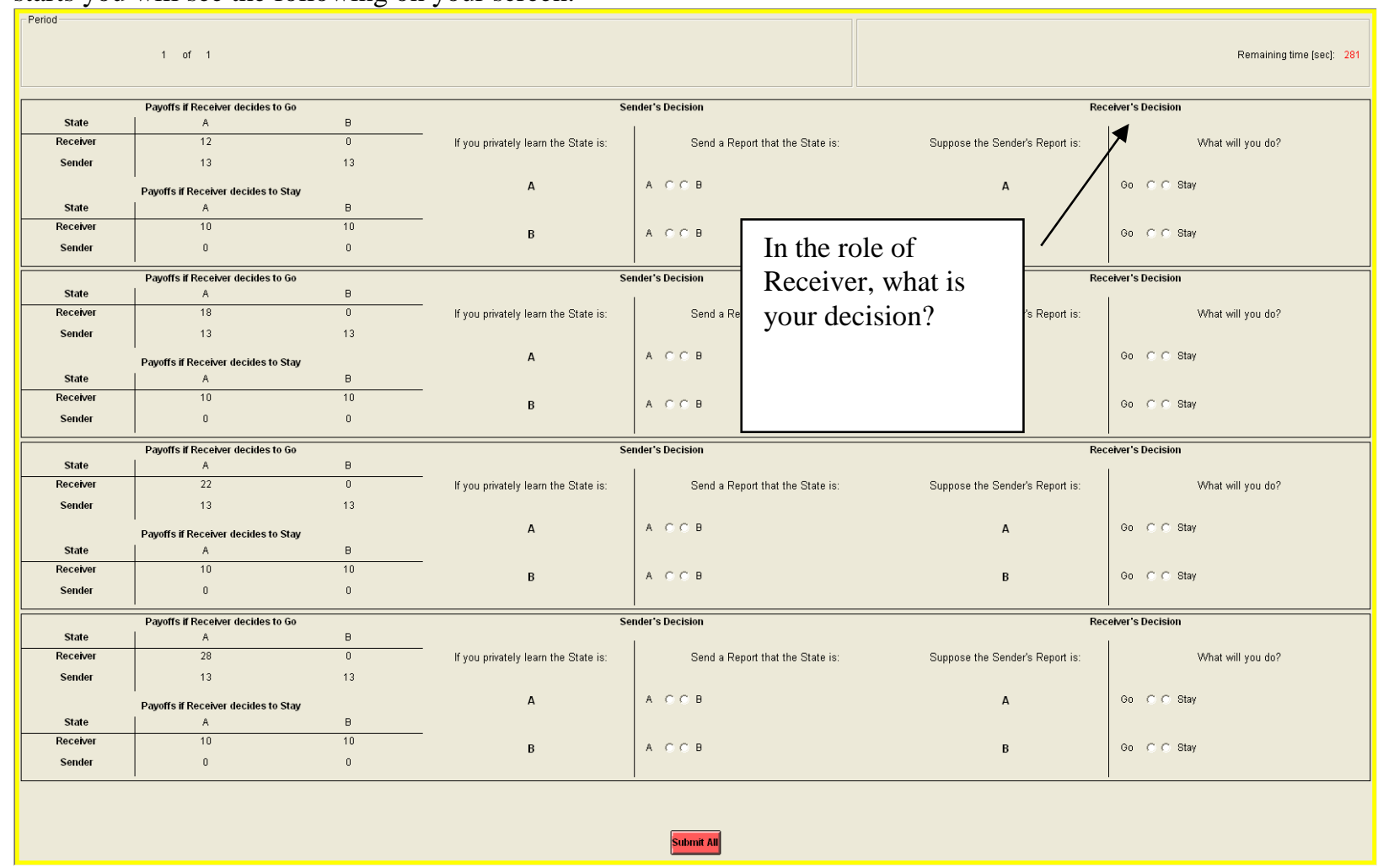

On the right side of the screen you are asked as a Receiver to fill in the two entries for each of four settings. If the Sender's Report were A, do you want to Go or Stay, and if the Sender's Report were B, do you want to Go or Stay? Although, in the end as a Receiver you would see only one Report (A or B), we still want you to tell us what you would do for each possible Report.

Your decision will not affect which Report is sent or which State drawn. Your decision in the role of Receiver will not effect the outcome of the settings in which you are a Sender.

\section{Questionnaire 2}

Below, please write down your answers to the following questions. In a few minutes, an experimenter will review the correct answers.

6) If the Sender always elects to report A, what report will the Receiver see when the State is A? (A, B)

7) If the Sender always elects to report A, what report will the Receiver see when the State is B? (A, B)

8) Does the Receiver always have to Go? (Yes, No)

9) If the Sender's Report is B, can the State be A? (Yes, No)

10) If the Sender's Report is A, can the State be B? (Yes, No)

\section{Results of the Round}

After you make both your decisions, the decision in the role of Sender and the decision in the role of Receiver, click on the red 'Submit' button. After all participants input their decisions, the computer will display the outcome screen with the outcome from one of the six settings. One, and only one, of your settings will be randomly selected and you will be paid on the outcome of that setting. For example, if the setting in which you played the role of Receiver was selected for payment, then your screen would show:

\begin{tabular}{|l|l|}
\multicolumn{1}{c|}{ Results of Setting } \\
\hline State & \\
\hline Sender's Report & \\
\hline Receiver's decision & \\
\hline
\end{tabular}




\begin{tabular}{|l|l|}
\hline Sender's payoff & \\
\hline Receiver's payoff & \\
\hline
\end{tabular}

How is this table generated? After all the participants have input their decisions, the computer will draw realizations of the State independently for each pair. The computer determines the State randomly as based on Chances of State table. Given the decision input by the Sender, the Report is determined and appears under the caption 'Sender's Report'. Note this is the Sender's Report - not the State.

Next, using the decision input by the Receiver, the computer reports if the Receiver decided to Stay or Go for the given Sender's Report. This decision is reported in the row titled 'Receiver's decision'. Finally, the computer determines the payoffs (taken from Payoffs Given State and Receiver's Decisions table) given the State and the decisions for the Sender and the Receiver. These payoffs are reported in the last two rows titled 'Sender's payoff' and 'Receiver's payoff'.

To summarize, the experiment consists of a single round where:

a. Grouping of Participants: pairs are randomly assigned

b. Participant's Decisions: each participant enters both a decision in the role of Sender and a decision in the role of Receiver.

c. Payoffs: the computer randomly selects one setting calculates payoffs using the decisions input

d. Results for the round: each participant sees payoff from the setting where he/she was the Sender or from the setting where he/she was the Receiver.

At the end of the experiment, you will be paid in private and in cash.

\section{Questionnaire 3}

Below, please write down your answers to the following questions. In a few minutes, an experimenter will review the correct answers.

11) You will be paid for one of your settings, not all. (True, False)

12) Suppose the setting where if the Receiver goes in State A he gets 18. If the State is A, the Sender reports ' $A$ ' when the State is $A$, and the Receiver decides to Go when the Report is ' $A$ ', what is:

a. The Sender's Report? $(\mathrm{A}, \mathrm{B})$

b. The Receiver's payoff? $(0,10,18)$

c. The Sender's payoff? $(0,13)$

\begin{tabular}{|l|l|}
\hline State & A \\
\hline Sender's Report & \\
\hline Receiver's decision & \\
\hline Sender's payoff & \\
\hline Receiver's payoff & \\
\hline
\end{tabular}

13) If the State is B, the Sender reports 'A' when the State is B, and Receiver decides to Stay when the Report is ' $A$ ', what is:

a. The Sender's Report? $(\mathrm{A}, \mathrm{B})$

b. Receiver's payoff? $(0,10,18)$

c. The Sender's payoff? $(0,13)$

\begin{tabular}{|l|l|}
\hline State & B \\
\hline Sender's Report & \\
\hline Receiver's decision & \\
\hline Sender's payoff & \\
\hline Receiver's payoff & \\
\hline
\end{tabular}




\section{Experimental Instructions: ROBOT treatment}

This is a computerized experiment in the economics of decision-making. By following the instructions carefully and making good decisions, you may earn an additional amount of money besides the show up bonus of \$7. The currency used in this experiment is the unit lira. Lira will be converted to dollars at the end of the experiment; the conversion rate is on the board. The actual amount of additional money that you may earn will depend on your decisions and the decisions of other participants. Your money will be paid to you in cash after the experiment ends.

There are some rules you must follow: (1) Do not talk to others at any time during the experiment. (2) You will use your computer to select decisions during the experiment. Do not use your mouse or keyboard to play around with the software running on your computer. If you unintentionally or intentionally close the software program running on your computer, you will be asked to leave. If this happens, you will receive only your show up bonus. (3) If you have any questions during the experiment or instructions, please raise your hand. An experimenter will come to your location and answer your questions.

\section{Details of a Past Experiment}

A past experiment was run in this laboratory using participants recruited the same way you were. The experiment consisted of a single round. Within the round people were randomly paired with other participants in each of four settings. Within each setting there was a single Sender and a single Receiver. Everyone made decisions as both as a Sender and a Receiver in all settings. These settings were separate, as decisions in one setting or role could not affect what happened in the other settings. No one was ever told whom he or she was paired with. They were not allowed to communicate with others during the experiment.

Each Receiver had one unit of the financial asset. At the end of each round, the computer determines the State of the economy, which in turn dictates the value of each Receiver's asset. The chances of a particular State were:

Chances of States
\begin{tabular}{|l|l|l|}
\hline State & A & B \\
\hline Chance of State & $1 / 2$ & $1 / 2$ \\
\hline
\end{tabular}

The State was either A or B. There was an equal chance that the computer will select A or B. So, on average the computer selects A 50 percent of the time and B 50 percent of the time. At the beginning of each round the Sender privately learned the State. No one else learned the State before the end of the round. After the Sender learned the State, the Sender sent a Report to the Receiver. After the Receiver saw the Sender's Report, the Receiver decided to Go or Stay resulting in the following payoffs.

Payoffs Given State and Receiver's Decisions

\begin{tabular}{|c|c|c|}
\hline State is & $\mathbf{A}$ & B \\
\hline \multicolumn{3}{|l|}{ Receiver decides to Go } \\
\hline Receiver & $\mathrm{X}$ & 0 \\
\hline Sender & 13 & 13 \\
\hline \multicolumn{3}{|l|}{ Receiver decides to Stay } \\
\hline Receiver & 10 & 10 \\
\hline Sender & 0 & 0 \\
\hline
\end{tabular}

The value of $\mathrm{X}$ depends upon the setting. It was 12, 18, 22, or 28 .

Notice that only when the State is A are the payoffs higher for all parties when the Receiver decided to Go rather than to Stay. Also, notice that the payoff is higher for the Sender if the Receiver decided to Go rather than to Stay in both States A and B. Last, notice that the payoffs do not depend on the Sender's Report, only on the State and whether the Receiver decided to Go or Stay.

What was the Sender's Report? If the Sender learned the State was A, the Sender could report either A or B. If the Sender learned the State is B, the Sender could Report A or B.

\section{Questionnaire 1}

Below, please write down your answers to the following questions. If you have a question, please raise your hand and an experimenter will privately answer your question. In a few minutes, an experimenter will review the correct answers. 
1) What was the chance the State was $B$ ? $(0,1 / 2,1)$

2) If the Sender knew the State is B, what could she report? (A, B, A or B)

3) If the Receiver knew the State was A, was his payment higher if he chose to Go? (Yes/No)

4) If the Receiver knew the State was $B$, was his payment higher if he chose to Go? (Yes/No)

5) If the Receiver decided to Go, what did the Sender receive? $(\$ 10, \$ 13)$

\section{Today's Experiment}

No one who was in the previous experiment is here today. In today's experiment, you are asked to make similar decisions as Sender and as a Receiver. However, unlike the previous experiment, you will NOT be paired with another person who is in the room today. Your payoff will be determined by your decisions and by a computerized decision process, which we will refer to as a "robot". So, unlike the prior experiment, your decisions cannot affect another other person's payoff. Furthermore, no other participant here today will make a decision affecting your payoff.

What exactly is the "robot"? The computer will randomly select from the archive of past observations in the past experiment and use one of the actual decisions to determine your payoffs. Your payoff as a Sender will depend upon your reporting decision, and the "robot" receiver. Your payoff as a Receiver will depend upon your decision to Stay or Go and the "robot" sender. Your decision cannot affect anyone else's payoff. Likewise, no one else's decision can affect your decision.

Let's examine more closely your decisions as Sender, and then as Receiver.

\section{Sender's Decision}

We will ask you to make a decision in the role of Sender in four settings. In each setting the payoff to the receiver if they go and the State is A is 12, 18, 22, or 28. Specifically, we will ask you to make a decision about what you would report to the paired Receiver in advance of seeing the State drawn. When the experiment starts you will see the following on your screen:

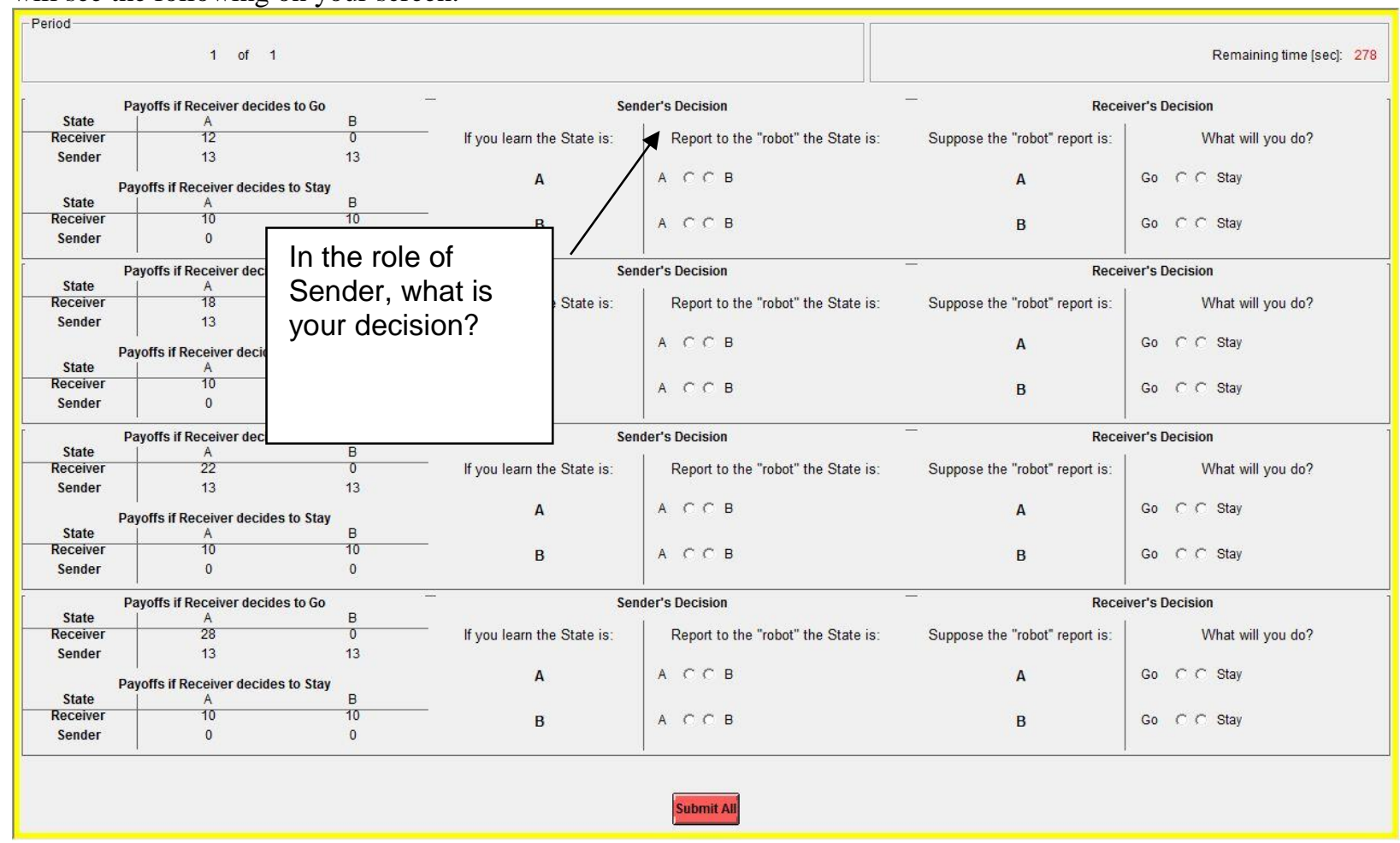

On the left side of the screen you are asked as a Sender to fill in the two entries for each of four settings. If the State were equal to A, would you report A or B, and if the State were equal to B, would you report A or B? Specifically, for each possible State, you need to tell the computer what Report you will send.

We want you, as the Sender, to say in advance what you would do in both of the scenarios. The computer implements the decisions you make once the State is drawn. Your decision will not affect which State is drawn. 
Your decision in the role of Sender will not affect the outcome of the settings in which you are a Receiver. Your decision in one setting will not affect the other settings. Your decision will affect anyone else's payoff.

\section{Receiver's Decision}

We will ask you to make a decision in the role of Receiver in four settings. Specifically, we will ask you to make a decision about what you would do for each possible Report the "robot" might send before you see the Report. When the experiment starts you will see the following on your screen:

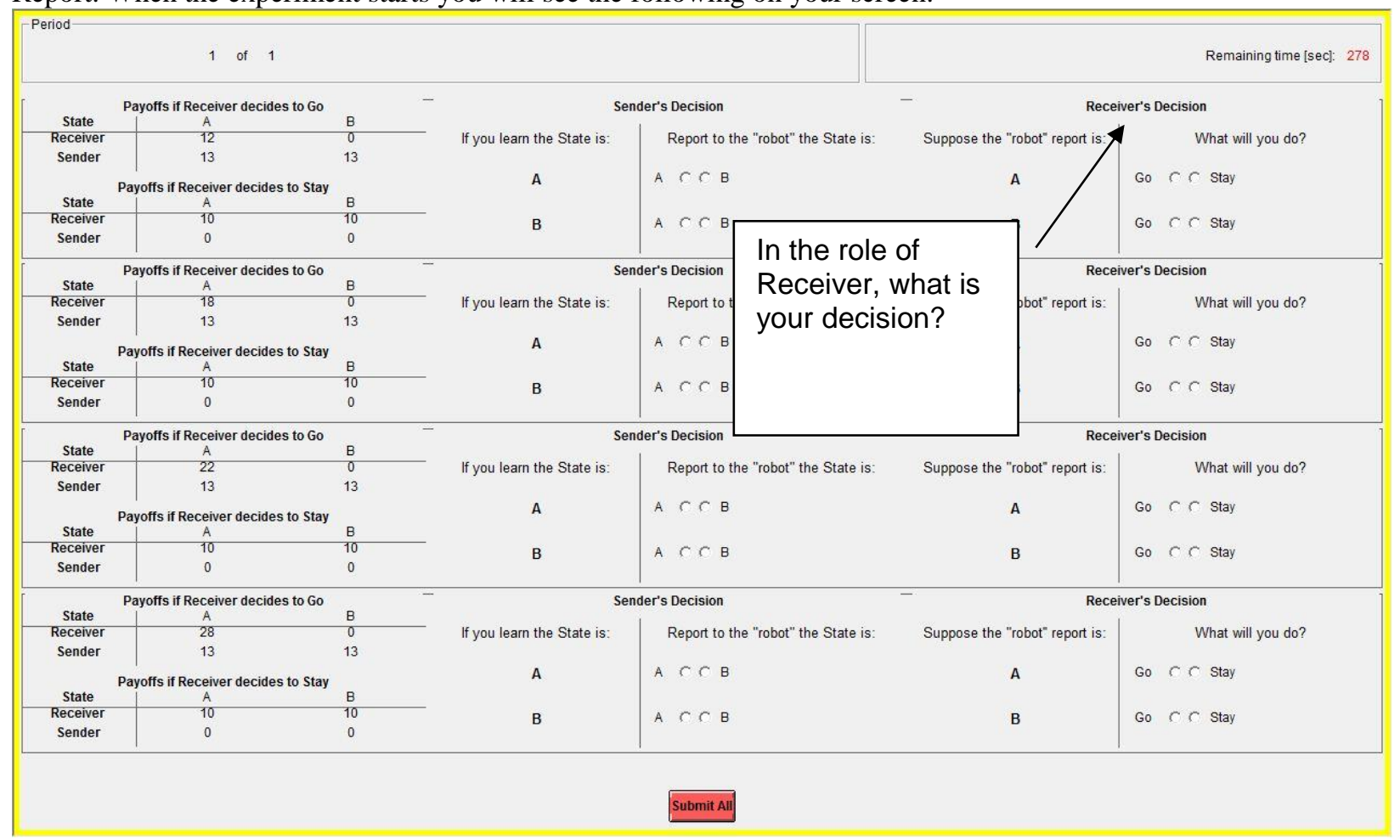

On the right side of the screen you are asked as a Receiver to fill in the two entries for each of four settings. If the "robot" Report was A, do you want to Go or Stay, and if the "robot" report was B, do you want to Go or Stay? Although, in the end as a Receiver you would see only one Report (A or B), we still want you to tell us what you would do for each possible Report.

Your decision will not affect which Report is sent or which State drawn. Your decision in the role of Receiver will not affect the outcome of the settings in which you are a Sender. Your decision in one setting will not affect the outcome in other settings. Last, your decision will affect anyone else's payoff.

\section{Questionnaire 2}

Below, please write down your answers to the following questions. In a few minutes, an experimenter will review the correct answers.

6) If the "robot" always elects to report A, what report will the Receiver see when the State is A? (A, B)

7) If the "robot" always elects to report A, what report will the Receiver see when the State is B? (A, B)

8) Does the Receiver always have to Go? (Yes/No)

9) If the "robot" Report is B, can the State be A? (Yes/No)

10) If the "robot" Report is A, can the State be B? (Yes/No)

11) Does your decision affect the payoffs of another? (Yes/No)

\section{Results of the Round}

After you make both your decisions, the decision in the role of Sender and the decision in the role of Receiver, click on the red 'Submit' button. After all participants input their decisions, the computer will display the outcome screen with the outcome from one of the six settings. One, and only one, of your settings will be randomly selected and you will be paid on the outcome of that setting. 
For example, if the setting in which you played the role of Receiver was selected for payment, then your screen would show:

\section{Results of Setting}

\begin{tabular}{|l|l|}
\hline State & \\
\hline Robot Report & \\
\hline Your decision & \\
\hline Your payoff & \\
\hline
\end{tabular}

How is this table generated? After all the participants have input their decisions, the computer will draw realizations of the State independently for each person. The computer determines the State randomly as based on Chances of State table. Given the decision of the "robot", the Report is determined and appears under the caption 'Robot Report'. Note this is the Report - not the State.

Next, using the decision input by you, the computer reports if you decided to Stay or Go for the "robot" Report. This decision is reported in the row titled 'Your decision'. Finally, the computer determines the payoffs (taken from Payoffs Given State and Receiver's Decisions table) given the State and the decisions of you and the "robot".

Alternatively, if the setting in which you played the role of Sender was selected for payment, then your screen would show:

\section{Results of Setting}

\begin{tabular}{|l|l|}
\hline State & \\
\hline Your Report & \\
\hline Robot decision & \\
\hline Your payoff & \\
\hline
\end{tabular}

As before, the computer determines the State randomly as based on Chances of State table. Given the decision input by you, the Report is determined and appears under the caption 'Your Report'. Next, using the decision of the "robot", the computer reports if the "robot" decided to Stay or Go given your Report. This decision is reported in the row titled 'Robot decision'. Finally, the computer determines the payoffs (taken from Payoffs Given State and Receiver's Decisions table) given the State and the decisions of you and the "robot".

To summarize, the experiment consists of a single round where:

a. Participant's Decisions: each participant enters both a decision in the role of Sender and a decision in the role of Receiver.

b. Payoffs: the computer randomly selects one setting calculates payoffs using the decisions input and a "robot" who randomly selects a decision from an archive of past experiments.

c. Results for the round: each participant sees payoff from the setting where he/she was the Sender or from the setting where he/she was the Receiver.

At the end of the experiment, you will be paid in private and in cash.

\section{Questionnaire 3}

Below, please write down your answers to the following questions. In a few minutes, an experimenter will review the correct answers.

12) You will be paid for one of your settings, not all. (True/False)

13) Suppose the setting where if the Receiver goes in State A he gets 18. If the State is A, the "robot" reports ' $A$ ' when the State is A, and the Receiver decides to Go when the Report is ' $A$ ', what is:

a. The "Robot" Report? (A, B)

b. The Receiver's payoff? $(0,10,18)$

\begin{tabular}{|l|l|}
\hline State & A \\
\hline Robot Report & \\
\hline Receiver's decision & \\
\hline Receiver's payoff & \\
\hline
\end{tabular}


14) If the State is B, the Sender reports ' $A$ ' when the State is B, and "robot" decides to Stay when the Report is ' $A$ ', what is:

a. The Sender's Report? (A, B)

b. The Sender's payoff? $(0,13)$

\begin{tabular}{|l|l|}
\hline State & B \\
\hline Sender's Report & \\
\hline Robot decision & \\
\hline Sender's payoff & \\
\hline
\end{tabular}

The following instructions were distributed after subjects completed the prior part of the experiment for both the REAL and ROBOT treatments

\section{Four Decision Problems}

In this part of the experiment you are asked to make a series of choices in 4 decision problems. How much you receive will depend partly on chance and partly on the choices you make. The decision problems are not designed to test you. What we want to know is what choices you would make in them. The only right answer is what you really would choose.

For each line in the table, please state whether you prefer option A or option B. Notice that there are a total of 4 lines in the table but only one line will be randomly selected for payment. Each line is equally likely to be selected, and you do not know which line will be selected when you make your choices. Hence you should pay attention to the choice you make in every line. After you have completed all your choices the computer will randomly drawn a number from 1 to 4 . The drawn number determines which line is going to be selected for payment.

Your earnings for the selected line depend on which option you chose: If you chose option A in that line, you will receive $\mathbf{\$ 1 0}$. If you chose option B in that line, you will receive either a positive amount or $\mathbf{\$ 0}$. To illustrate, say the line drawn for payment is 2 . To determine your earnings another number is randomly drawn from $\mathbf{1}$ to $\mathbf{2}$. The drawn number is then compared with the numbers in the line selected (see the table). If the drawn number is 1 you earn $\$ 18$, but if the drawn number is 2 you earn $\$ 0$.

While you have all the information in the table, we ask you that you input all your choices into the computer. The actual earnings for this part will be determined at the end, and will be independent of the prior portions.

\begin{tabular}{|l|c|l|l|}
\hline & Option A & \multicolumn{2}{|c|}{ Option B } \\
\hline 1 & $\mathbf{\$ 1 0}$ & $\mathbf{\$ 1 2}$ if 1 is drawn & $\mathbf{\$ 0}$ if 2 is drawn \\
\hline 2 & $\mathbf{\$ 1 0}$ & $\mathbf{\$ 1 8}$ if 1 is drawn & $\mathbf{\$ 0}$ if 2 is drawn \\
\hline 3 & $\mathbf{\$ 1 0}$ & $\mathbf{\$ 2 2}$ if 1 is drawn & $\mathbf{\$ 0}$ if 2 is drawn \\
\hline 4 & $\mathbf{\$ 1 0}$ & $\mathbf{\$ 2 8}$ if 1 is drawn & $\mathbf{\$ 0}$ if 2 is drawn \\
\hline
\end{tabular}

